\title{
Abriendo brechas en la coraza de la investigación educativa hegemónica
}

\section{Breaking new grounds in the hegemonical educational research front}

Manuel Fernández Navas, J. Eduardo Sierra Nieto, Noelia Alcaraz Salarirche, Ester Caparrós Martín, Diego Martín Alonso, Mayka García García, Álvaro Pérez García y Laura Pérez Granados Equipo editorial

Si bien en el último cuarto del siglo XX se dio lo que se vino a llamar "Guerra de los paradigmas", su finalización ha estado lejos de concretarse en un statu quo en el que convivan diferentes metodologías de investigación y sus marcos epistemológicos y ontológicos aparejados. Más bien, lo que venimos viviendo en las últimas dos décadas es la consolidación de unos planteamientos muy encorsetados por el paradigma positivista en sus nuevas (o no tanto) formulaciones, como lo que se ha venido a llamar "investigación basada en la evidencia". Así, palabras como "ciencia", "evidencia", "datos" o "rigor", han dejado de tener un significado amplio para entenderse casi en exclusiva desde el prisma de la metodología cuantitativa. Esto es así hasta el punto de que hacer investigaciones que no tengan que ver con métodos experimentales o cuasiexperimentales es calificado de no científico.

No cabe duda de que uno de los ámbitos de poder más claros en el mundo universitario son las revistas científicas. Estas suponen el espacio privilegiado para que el profesorado comunique sus trabajos, resultando decisivas para que el profesorado obtenga el puntaje necesario para avanzar en sus carreras profesionales, buscando la estabilización laboral.

Es fácil advertir que en nuestro país (si bien es una situación extensiva a otros contextos, tal y como podemos compartir con colegas de otros países), la investigación educativa está fuertemente orientada hacia (y por) el paradigma positivista basado en métodos cuantitativos. Esto no sería un problema si fuera una elección, pero la realidad es que es una obligación a la que muchas veces investigadoras e investigadores se ven avocados. Una breve ojeada al panorama español de revistas educativas nos deja ver que la inmensa mayoría prioriza estudios cuantitativos (cualquiera que haya intentado publicar un estudio cualitativo sabe a qué nos referimos).

Creemos que es nuestra responsabilidad como investigadoras e investigadores actuar para transformar esta situación en nuestros contextos más cercanos. Así, nos hacemos eco de las reflexiones de Given (2017, p. 2) cuando se pregunta ¿Cómo podemos detener esta guerra de paradigmas?

Podemos educar a los estudiantes y colegas de investigación sobre la naturaleza del paradigma cualitativo y cómo influye en nuestros métodos, nuestros análisis y nuestras técnicas de escritura. Podemos corregir editores y revisores de revistas cu- 


\section{$\begin{array}{llllllllll}\text { E } & \text { D } & \text { I } & \text { T } & \text { O } & \text { R } & \text { I } & \text { A } & \text { L }\end{array}$}

ando solicitan cambios que no se ajustan a la naturaleza del paradigma cualitativo. Podemos desafiar las críticas o los despidos de nuestros compañeros (en paneles de concesión, paneles de promoción o en nuestros pasillos académicos) de diseños cualitativos apropiados. En resumen, ipodemos defendernos como expertos en paradigmas cualitativos!

A nuestro modo de ver, esto empieza por crear espacios donde la investigación cualitativa tenga cabida. Espacios como esta revista, la cual esperamos que vaya creciendo y conformándose como un lugar de referencia para aquellos profesionales de la educación que quieren profundizar sobre otra forma de entender la investigación en educación o difundir sus "evidencias", su "ciencia", sin que esta tenga que ser positivista, cuantitativa; y sin que ésta pase por ser considerada como investigación poco rigurosa o por ciencia de bajo nivel. En este sentido, creemos que es el momento de recuperar la reflexión sobre qué significa investigar. Una reflexión abierta y profunda sobre cuestiones epistemológicas, axiológicas y ontológicas, pues estamos convencidos de que una de las críticas que se vierte sobre estos enfoques -el que se trata de filosofía o, más despectivamente, de filosofar- es en realidad su virtud y su fortaleza, pues el desarrollo de la ciencia, de cualquier ciencia (social o natural), surge de la tensión entre paradigmas; es la forma natural con la que se desarrolla el conocimiento en cualquier ámbito, como aprendimos hace décadas con Thomas Kuhn.

Desde Márgenes estamos preocupados por la situación descrita, de ahí que hayamos querido poner el foco en este número temático en cuestiones como las siguientes: ¿Qué está ocurriendo en nuestro país con la investigación educativa? ¿Qué consecuencias tiene esta visión hegemónica de lo que es investigar y producir conocimiento? ¿Cómo afecta a la formación de futuras investigadoras e investigadores? ¿Qué consecuencias tiene el "publica o perece" que parece haberse instaurado en el mundo académico? Si se priorizan publicaciones desde una determinada visión metodológica, ¿se está invisibilizando a las demás? ¿Cómo se transforma la práctica educativa con esta situación? ¿Hacer investigación rigurosa es únicamente hacer investigación cuantitativa? ¿De qué tipo de rigurosidad estamos hablando?

Todas estas cuestiones son abordadas en este número monográfico de Márgenes que tiene por título “¿Hacia dónde va la investigación educativa?”, en consonancia y en continuidad con nuestro $\mathrm{n}-0$. A nuestro equipo editorial le parecía que este debía ser un número crítico con el que invitar a quiénes nos leen a repensar todas aquellas cuestiones relacionadas con la investigación en educación en nuestro país, muchas de las cuales pasan desapercibidas en el día a día puesto que las tenemos interiorizadas, asumidas.

Esperamos que el número cumpla con tal propósito, y que su lectura resulte estimulante y provocadora, invitando a repensar el mencionado statu quo y contribuyendo a encontrar argumentos y perspectivas que apoyen el trabajo que muchas investigadoras y muchos investigadores vienen haciendo desde enfoques cualitativos. Y, sobre todo, esperando que resulte un número útil y valioso para reflexionar sobre un asunto tan relevante como la forma en la que se genera el conocimiento en nuestro campo.

¿Estás preparado para salirte de los paréntesis del pensamiento hegemónico y adentrarte en los Márgenes? 